\title{
Teoria da Estruturação Forte Aplicada aos Estudos Organizacionais
}

\author{
Strong Structuration Theory Applied to Organizational Studies
}

Miguel Rivera Peres Jr.

Professor do Departamento de Gestão do Instituto Federal de Educação, Ciência e Tecnologia de Minas Gerais - IFMG - Campus

Formiga. Formiga, MG. Brasil. E-mail: miguel.peres@ifmg.edu.br

José Roberto Pereira

Professor associado da Universidade Federal de Lavras (UFLA). Lavras, MG. Brasil.E-mail: jrobertopereira2013@gmail.com

\section{Resumo}

A Teoria da Estruturação do sociólogo Anthony Giddens tem, ao longo dos últimos anos, sido utilizada em diversos trabalhos em uma gama extensa de áreas de estudo, e, dentre tais áreas, é possível destacar os estudos organizacionais. A despeito dessa intensa utilização, a Teoria da Estruturação foi alvo de várias críticas e revisões, como a feita por Stones (2005), que redundou na proposição da "Teoria da Estruturação Forte" (Strong Structuration Theory). Este artigo objetiva apresentar as principais concepções da Teoria da Estruturação Forte, cotejando-as com os fundamentos da Teoria da Estruturação e fornecendo insights iniciais para investigações em estudos organizacionais, a partir dessa perspectiva teórica. Para o alcance desse objetivo, foi feita revisão bibliográfica crítica das duas teorias que, ao final, possibilitou a indicação de algumas possibilidades de investigações no âmbito organizacional com a utilização da Teoria da Estruturação Forte, em particular a partir da ontologia, in situ, proposta por Stones (2005).

Palavras-chave: Teoria da Estruturação. Estudos Organizacionais. Teoria da Estruturação Forte. Organizações. Agência e Estrutura.

\section{Abstract}

The Structuration Theory of the sociologist Anthony Giddens has been, over the past few years, used in several works on a wide range of subject areas and among them, highlights the organizational studies. Despite this extensive use, the Structuration Theory was the target of a lot of criticism and review, as done by Stones (2005), which resulted in the proposal of "Strong Structuration Theory". This article objective present the main concepts of the Strong Structuration Theory, comparing them with the fundamentals of the Structuration Theory and providing initial insights for research in organizational studies, from this theoretical perspective. To achieve this objective was done a critical literature review of the two theories that at the end, allowed the indication of some possible investigations into the organizational scope with the Strong Structuration Theory, in particular from the ontology in situ, proposed by Stones (2005).

Keywords: Structuration Theory. Organizational Studies. Strong Structuration Theory. Organizations. Agency and Structure. 


\section{INTRODUÇÃo}

A ação $e$ a estrutura são, em geral, assumidas como conceitos opostos na sociologia e na filosofia e têm, ao longo do tempo, suscitado intensas discussões teóricas no campo das Ciências Sociais. O embate, no entanto, tem se mostrado salutar, uma vez que deu origem a empreendimentos teóricos que tentam abordar as duas dimensões de forma não dicotômica. As teorias que abordam a relação entre estrutura social e agência humana de forma não dualística têm, no entendimento de Schilling (1999, p. 543), estimulado um dos debates mais produtivos no âmbito da sociologia, ao confrontar questões que são centrais para a disciplina.

Dentre essas teorias, insere-se a Teoria da Estruturação de Anthony Giddens. É justamente na tentativa de articulação entre essas duas concepções - ação $e$ estrutura - que derivam praticamente todas as conceituações que embasam a Teoria da Estruturação, que se vale, fundamentalmente, da premissa de que o dualismo ação-estrutura deve ser reconceituado dualidade da estrutura (GIDDENS, 1989, p. XVII). A dualidade da estrutura constitui, claramente, a unidade de análise da Teoria da Estruturação (DOMINGUES, 2008, p. 63) e tem papel nuclear no pensamento giddensiano. (PIRES, 2000, p. XII)

Na conceituação de dualidade da estrutura, postula-se que as propriedades estruturais dos sistemas sociais são, simultaneamente, condição e resultado da ação, meio e resultante das práticas sociais que ela, recursivamente, organiza. Ao mesmo tempo, assume-se que a estrutura constitui fator de constrangimento $e$ de possibilitação da agência (GIDDENS, 1989; 2000). A partir dessas premissas, Giddens (2000, p. 43) defende que uma das tarefas específicas da teoria social deve ser o "[...] estudo das condições que presidem a organização dos sistemas sociais que governam as articulações entre constrangimento e capacitação".

A Teoria da Estruturação tem sido utilizada em trabalhos nas mais diversas áreas do conhecimento (BRYANT; JARY, 2001; PHIPPS, 2001). No campo de estudos organizacionais, também é significativo o número de trabalhos desenvolvidos com suporte na Teoria da Estruturação. Conforme afirma Rodrigues (2008, p. 38), os "[...] estudos organizacionais tornaram-se uma arena rica para discussões sobre as possibilidades de uso da teoria de Giddens para fenômenos organizacionais". Ranson, Hinings e Greenwood (1980), Barley (1986), Whittington (1992), Junquilho (2003), Pozzebon (2004), Pozzebon e Pinssoneualt (2005), Albano, Masino e Maggi (2010), dentre outros, também destacam a importância da Teoria da Estruturação como ferramenta para a análise do fenômeno organizacional.

Uma característica que marca o uso da Teoria da Estruturação em estudos organizacionais (e também em outras áreas) é sua recorrente revisão, adaptação, ou modificação, promovida por outros autores. Exemplos dessas iniciativas podem ser observados em Whittington (1992), o autor sugere um framework que reconhece a diversidade de princípios estruturais que afetam (constrangendo ou habilitando) a ação gerencial; e em DeSanctis e Poole (1994, p. 142), que propõem a teoria da estruturação adaptativa (Adaptive Structuration Theory - AST), a fim de estudar o impacto da tecnologia da informação no ambiente organizacional.

Esforço mais recente de revisão da Teoria da Estruturação vem sendo feito pelo sociólogo - inglês, como Giddens - Rob Stones. Em seu livro de 2005, Structuration Theory, o autor discute a Teoria da Estruturação, apresentado seus principais conceitos e concepções ontológicas e epistemológicas fazendo, ao mesmo tempo, a proposta de um novo arcabouço que é definido como uma "[...] síntese que recorre e é baseada nas críticas, debates, defesas e refinamentos que existem no campo da estruturação, ao mesmo tempo em que extrai lições de muitas das aplicações da teoria no nível substantivo" (STONES, 2005, p. 1, tradução nossa). A esse arcabouço teórico, o autor dá o nome de "Teoria da Estruturação Forte"1 (Strong Structuration Theory)

Este artigo tem, como propósito central, apresentar e discutir algumas das acepções centrais da "Teoria da Estruturação Forte", que podem ser aplicadas aos estudos organizacionais. Entende-se que essa teoria, ao mesmo tempo em que consolida alguns dos princípios ontológicos e epistemológicos gerais da Teoria da Estruturação giddensiana, já amplamente utilizados nos estudos organizacionais, traz uma alternativa profícua para a investigação do fenômeno organizacional por meio da propositura de uma ontologia, in situ - circunstâncias substantivas que, segundo Stones (2005), a Teoria da Estruturação negligenciaria. 
Para o alcance desse objetivo, serão apresentados, inicialmente, alguns dos principais conceitos propostos na Teoria da Estruturação. Posteriormente, far-se-á o mesmo com as concepções da "Teoria da Estruturação Forte", sugerindo, ao cabo, possíveis aplicações aos estudos organizacionais.

\section{Teoria da Estruturação: FUNDAMENTOS E CARACTERÍSTICAS}

O debate acerca da preponderância da estrutura sobre a ação do homem, ou sobre a prevalência da agência na determinação das estruturas é um dos mais intensos no âmbito das Ciências Sociais. Para Berard (2005, p. 197) "[...] a relação entre práticas e estruturas não só se tornou um tema, há muito tempo na teoria sociológica, como também é agora, provavelmente, a preocupação maior (tradução nossa)". No cerne desse embate está, de um lado, a defesa - por parte dos teóricos situados nas perspectivas naturalistas, funcionalistas e estruturalistas, dentre outras - da prevalência da estrutura como unidade de análise principal. Em oposição a essa vertente, encontram-se aqueles teóricos que defendem o sujeito (ou a ação) como sendo a unidade de análise a ser priorizada pelas ciências sociais. (ALEXANDER, 1987)

A Teoria da Estruturação parte da premissa de que esse dualismo objetivismo-subjetivismo (ou ação-estrutura) deve ser superado, ou melhor, reconstituído como dualidade - a dualidade da estrutura (GIDDENS, 1989, p. XVII). A dualidade da estrutura baseia-se na concepção de que as propriedades estruturais dos sistemas sociais são simultaneamente o meio e o resultado das práticas que constituem esses mesmos modelos. (GIDDENS, 2000, p. 43)

A estrutura é, assim, simultaneamente condição e resultado da ação, fator de constrangimento e de possibilitação da agência, meio e resultante das práticas sociais que ela, recursivamente, organiza. A partir dessa proposição, Giddens (2000, p. 43) defende que "[...] o estudo das condições que presidem a organização dos sistemas sociais que governam as articulações entre constrangimento e capacitação constitui uma das tarefas específicas da teoria social".

Para Giddens (1989, p. 13-14), a estrutura, na análise social, deve ser entendida como as "[...] pro- priedades de estruturação que permitem a "delimitação' de tempo-espaço em sistemas sociais”. São essas propriedades que constituem uma ordem virtual de relações transformadoras que permitem a existência das práticas sociais, discerníveis por dimensões variáveis de tempo e espaço, e que lhes emprestam uma forma sistêmica. É importante salientar que os sistemas sociais - formados pelas práticas sociais - não "têm" estruturas, mas exibem propriedades estruturais, entendidas como regras e recursos, recursivamente implicados na reprodução dos sistemas sociais (GIDDENS, 2000, p. 31) e que "[...] a estrutura só existe, como presença espaço-temporal, em suas exemplificações em tais práticas e como mnêmicos orientando a conduta de agentes humanos" (GIDDENS, 1989, p. 13-14). Percebe-se que, diferentemente do funcionalismo, na Teoria da Estruturação a estrutura não é vista como a análise descritiva das relações de interação que "compõem" organizações e coletividades, mas sim como sistema de regras e recursos geradores (ou gerativos).

$\mathrm{Na}$ Teoria da Estruturação, as regras da vida social são assumidas como técnicas ou procedimentos generalizáveis aplicados no desempenho ou reprodução de práticas sociais. É importante não confundi-las com as regras formuladas - aquelas que recebem expressão verbal, como leis, normas burocráticas, regras de jogos, etc. - que são apenas interpretações codificadas das regras, e não regras como tais. (GIDDENS, 1989, p. 17)

Giddens (2001, p. 145) estabelece, para fins analíticos, dois tipos de regras. O primeiro tipo, ele denomina regras semânticas, que englobam as regras de sintaxe e gramaticais (ver-se-á, mais a frente, que o autor atribui importância crucial à linguagem no processo de (re)produção social) - e a totalidade das regras, geralmente implícitas, que estruturam o discurso cotidiano e o entendimento mútuo (também chamadas de esquemas interpretativos). As regras morais constituem o segundo tipo e compreendem qualquer tipo de regra que possibilite a avaliação de atos como "certos" ou "errados".

Já os recursos, a outra propriedade estruturante, são entendidos como “[...] as 'bases' ou os 'veículos' do poder, incluindo as estruturas de dominação mobilizadas pelas partes em interação e reproduzidas através da dualidade da estrutura" (GIDDENS, 2000, p. 41-42). Na concepção de Giddens, recursos e poder 
são dois aspectos da realidade social que se encontram absolutamente interligados.

Dois tipos de recursos são considerados como vetores de dominação. Os recursos alocativos, que são recursos materiais envolvidos na geração de poder e que proveem do domínio sobre a natureza. Já os recursos autoritários, são de ordem não material e derivam da capacidade de tirar proveito das atividades de seres humanos, resultando no domínio de determinados atores sobre outros. (GIDDENS, 1989, p. 304)

A partir dessa singular definição de estrutura $e$ percebendo limitações no uso do conceito "estrutura", tanto no funcionalismo quanto no estruturalismo, Giddens (1978, p. 127-128) introduz a noção de estruturação na tentativa de reconhecer a constituição da vida social como resultante da produção de sujeitos ativos. A estruturação, como fenômeno, é definida como as "[...] condições que regem a continuidade ou a transformação das estruturas e, como tal, a reprodução dos sistemas" (GIDDENS, 2000, p. 36). Analisar a estruturação do sistema social corresponde assim, a "[...] estudar os modos pelos quais esse mesmo sistema, por via da aplicação de regras e recursos generativos, e no contexto de resultados não intencionais, se produz e reproduz através da interação". (GIDDENS, 2000, p. 35)

Nos processos de estruturação ocorre a união entre a integração estrutural, que é a transformação das coletividades ou organizações (enquanto sistemas), com a integração social, entendida como a transformação da interação no nível do mundo vivo (GIDDENS, 1978, p. 132). Ele ressalta, no entanto, que integração - na sua concepção - não é sinônimo nem de coesão, nem, certamente, de consenso, referindose, basicamente, a um grau de interdependência da ação, ou "sistematicidade", que se encontra presente em qualquer modo de reprodução sistêmica, podendo, ainda, ser caracterizada como laços regularizados, ou como a reciprocidade das práticas, quer entre atores quer entre coletividades. (GIDDENS, 2000, p. 57-58)

Também o conceito de sistemas sociais utilizado na Teoria da Estruturação traz algumas diferenciações uma vez que, de acordo com Giddens (1989, p. 305), sistema é a padronização de relações sociais ao longo do espaço-tempo, entendidas como práticas reproduzidas. Sendo assim, os sistemas sociais implicam relações regularizadas de interdependência entre indivíduos e grupos, que nas suas formas mais típicas podem ser analisadas como práticas sociais recorrentes. Importante destacar que os sistemas possuem propriedades estruturais, mas não são, eles próprios, estruturas. (GIDDENS, 2000, p. 35)

$\mathrm{Na}$ perspectiva estruturacionista, a produção $e$ constituição da sociedade são assumidas como resultantes da prática de seus membros e a chave para entender a ordem social - em seu sentido mais amplo - não está na interiorização de valores (como defende a teoria estrutural-funcionalista), mas nas inter-relações de produção e reprodução da vida social por seus atores cognoscitivos por meio de práticas recursivas (GIDDENS, 1978, p. 104). A cognoscitividade, para Giddens (1989, p. 301), é tudo que os atores sabem (de forma tácita ou discursiva) sobre as circunstâncias das ações (suas e dos outros agentes), com base na produção e reprodução dessas. Ao mesmo tempo, ele argumenta que "[...] as capacidades reflexivas do ator humano estão caracteristicamente envolvidas, de um modo contínuo, no fluxo da conduta cotidiana, nos contextos da atividade social" (GIDDENS, 1989, p. XVIII-XIX). Por outro lado, a recursividade indica que as práticas humanas não são criadas pelos atores sociais, mas sim recriadas por eles. Ao desempenhar suas atividades, e, através destas, os agentes contribuem para a reprodução das condições que tornam essas mesmas atividades possíveis. (GIDDENS, 1989, p. 2)

Assume-se, assim, que a produção da sociedade é sempre, e em todo lugar, uma realização habilitada, reflexiva e de caráter recursivo de seus membros. No entanto, diferentemente das outras escolas de sociologia compreensiva, Giddens (1978, p. 134) alerta que é necessário reconhecer que se os homens criam a sociedade, eles não o fazem somente sob as condições que eles mesmos escolheram. É fundamental complementar a ideia da produção da vida social com a ideia de reprodução social das estruturas.

Partindo desses pressupostos, Giddens (1989) defende que nos processos de reprodução social a mediação entre estrutura e interação se dá por meio das "modalidades" e envolve três elementos fundamentais: comunicação, poder e moral (ou sanção). Esses três elementos estão presentes na interação e se relacionam com aspectos estruturais correspondentes - significação, dominação e legitimação - por meio de modalidades também específicas a cada uma das 
dimensões: esquemas interpretativos, facilidades $e$ normas (Figura 1).

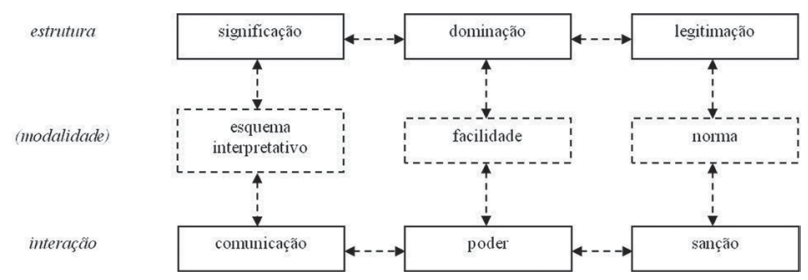

Figura 1: Dualidade da estrutura em interação Fonte: Giddens (1989, p. 23)

A comunicação do significado na interação pressupõe o uso de esquemas interpretativos por meio dos quais os atores interpretam o que o outro diz ou fala. A utilização desses esquemas depende de uma "ordem cognitiva", de um quadro de conhecimento mútuo que ao mesmo tempo em que permite a comunicação, é modificada pela interação, uma vez que a aplicação dos esquemas interpretativos reconstitui essa ordem. Já o uso do poder na interação envolve a utilização de facilidades (recursos) que permitem aos participantes o alcance de resultados pretendidos (ou não) que afetam a conduta dos outros. A utilização dessas facilidades pode levar à dominação que, por sua vez, pode potencializar o acesso aos recursos disponíveis reproduzindo essa ordem. Finalmente, na constituição moral da interação, observa-se que a utilização de normas derivadas de uma ordem legítima acaba por reforçar essa mesma legitimidade. (GIDDENS, 1978, p. 129-130)

É importante ressaltar que essas dimensões da interação e da estrutura só são separáveis analiticamente. No processo de interação esses elementos estão inextricavelmente relacionados em todas as práticas sociais. No decorrer da interação, a comunicação de sentido, por exemplo, não tem lugar separadamente do modo como as relações de poder funcionam, ou fora do contexto das sanções normativas. (GIDDENS, 2000, p. 67-68)

Por ultimo, cabe discutir, mesmo que brevemente, o modelo de estratificação da ação de Giddens (1989, p. 4-11). Segundo ele, a ação apresenta três momentos distintos: motivação, racionalização e monitoração reflexiva. A monitoração reflexiva da ação refere-se ao controle e a regulação que os agentes continuamente fazem de seu fluxo de atividades. Esse monitoramento reflexivo é uma característica crônica da ação cotidiana e envolve as atividades do próprio ator e as dos demais, assim como os aspectos sociais e físicos do contexto (GIDDENS, 1989, p. 4-5). A racionalização da ação parte da assunção de que os atores possuem um "entendimento teórico" a respeito daquilo que fazem. Possuir tal entendimento, não significa, no entanto, dizer que os atores tem a capacidade de sempre especificar discursivamente as razões de suas ações. Há ações que estão de tal forma imbricadas no cotidiano dos atores que eles têm dificuldade em explicar suas razões ou intenções. Já motivos geralmente têm uma influência mais direta na ação em circunstâncias que, de algum modo, fogem da rotina. (GIDDENS, 1989, p. 4-5)

Há dois outros elementos que compõem o modelo de estratificação do agente: as consequências impremeditadas da ação $e$ as condições não reconhecidas da ação. A duração (durée) da vida cotidiana ocorre como um fluxo contínuo de ação intencional. Os atos intencionais têm, no entanto, consequências não intencionais, não desejadas ou esperadas. Toda ação traz consequências e, por vezes, um ato aparentemente trivial pode deflagrar eventos distanciados dele no tempo e no espaço, que podem ser de enorme complexidade e não estão relacionados diretamente à premeditação ou não das consequências. Ao mesmo tempo, ao agir, o ator não é motivado apenas por motivos conscientes. Há uma série de motivos inconscientes - denominadas condições não reconhecidas da ação - que influenciam na agência. (GIDDENS, 1989, p. 6-11)

Diversos outros conceitos singulares formam a estrutura teórica da Teoria da Estruturação. Claro que não se pretende, neste trabalho, trazer à tona toda a complexidade de definições que a constituem. Esperase, contudo, que alguns dos aspectos centrais da Teoria da Estruturação tenham sido apresentados e discutidos de forma minimamente suficiente para a compreensão dos "avanços" trazidos pela "Teoria da Estruturação Forte", discutida mais adiante.

\section{Estudos de Perspectiva ESTRUTURACIONISTA: CRÍTICAS E APLICAÇÕES}

O esforço despendido por Anthony Giddens para elaborar os pressupostos da estruturação, com pretensões de ser uma teoria geral, foi - e ainda é - alvo de críticas. Obviamente que, uma iniciativa de tal enver- 
gadura, que procura abarcar um leque absolutamente extenso de dimensões da vida social, passaria pelo crivo rigoroso de seus pares.

Dentre os principais críticos da Teoria da Estruturação, destacam-se Thompson (1989), Parker (2000), Sewell Jr. (1992), Archer (1982), Bhaskar (1998) e Mouzelis (1989). De forma sintética e geral, pode-se afirmar que as principais críticas feitas são em relação à conceituação de estrutura como virtual, dual e indistinguível da ação (ARCHER, 1982; BHASKAR, 1998; MOUZELIS, 1989; PARKER, 2000). Para esses críticos, é fundamental restabelecer o dualismo entre estrutura $e$ agência, uma vez que elas possuem "identidades" singulares, mesmo que se reconheça sua interdependência. A conceituação de estrutura, como sendo composta de regras e recursos, é criticada em razão da falta de detalhamento nos textos de Giddens sobre sua origem e natureza (THOMPSON, 1989). Outra crítica recorrente à Teoria da Estruturação refere-se à dificuldade de aplicação prática de suas concepções. (STONES, 2005; POZZEBON; PINSSONEAULT, 2005)

Mesmo submetida a essas (e outras críticas), a Teoria da Estruturação tem sido utilizada em trabalhos nas mais diversas áreas como, por exemplo, sistemas contábeis, arqueologia, demografia, cultura organizacional, política, sociologia da tecnologia, gestão de redes interfirmas, estudos migratórios, análises do esporte e lazer, e sobre gênero e patriarcado (BRYANT; JARY, 2001, p. 43-61). Phipps (2001), analisando 53 obras (artigos, livros, capítulos de livros e teses) que empregaram a Teoria da Estruturação empiricamente, também identificou uma gama extensa de áreas e temas, dentre eles, vários estudos relacionados às organizações.

Para Giddens (1987, p. 155), "[...] o mundo moderno é o mundo das organizações [...]" e, sendo assim, as organizações assumem papel central na Teoria da Estruturação. Na perspectiva estruturacionista as organizações são consideradas como "compartimentos de poder", uma vez que são centros de concentração de recursos materiais e políticos (ou autoritários e alocativos, como já mencionado). Constituem, ao mesmo tempo, coletividades nas quais o conhecimento sobre as condições de reprodução do sistema é utilizado reflexivamente para influenciar, dar forma ou modificar esse mesmo sistema (GIDDENS, 2008, p. 38-39). Nesse sentido, os estudos organizacionais constituem um campo fértil para a perspectiva estruturacionista uma vez que "[...] o nível organizacional é aquele em que a relação entre agência e estrutura é mais visivelmente representada" (MACHADO-DA-SILVA; GUARIDO FILHO; ROSSONI, 2006, p. 180). Reed (1997, p. 21) acrescenta que o debate agência/estrutura força os pesquisadores organizacionais a se confrontarem com uma série de questões que, "[...] irremediavelmente, definem a constituição de seu objeto de estudo e os termos analíticos e metodológicos pelos quais ele deve ser pesquisado e explicado".

Atentos a essas premissas, pesquisadores organizacionais têm adotado a lente estruturacionista desde a década de 1980 (POZZEBON, 2004; WHITTINGTON, 1992), movimento que persiste ao longo dos primeiros anos do século XXI. Ao se fazer uma pesquisa na base de dados Web of Science (WoS), reforça-se essa constatação. A procura pelo termo "structuration theory" no campo "topic" - que pesquisa nos títulos, abstracts e palavras-chave dos artigos - retorna 357 artigos, publicados entre 1986 e 2011. A busca indicou a ocorrência do termo "structuration theory" em artigos vinculados a 67 categorias (áreas) de estudo estabelecidas pela WoS.

Nessa mesma pesquisa, pôde-se observar a relevância da Teoria da Estruturação para os estudos ligados às organizações, uma vez que, a área "gestão" (management) é a categoria com maior número de artigos - 88 , ou $24,6 \%$ do total. Se forem agregadas as categorias "negócios" e "negócios financeiros", o peso da área vai para 33,9\% - mais de 1/3 dos trabalhos listados. A relação dos periódicos com maior número de publicações com a utilização da Teoria da Estruturação corrobora essa tese uma vez que, entre os dez primeiros colocados, metade dos periódicos está direta ou indiretamente ligada aos estudos organizacionais: Organization Science $\left(1^{\circ}\right)$; Organization Studies $\left(3^{\circ}\right)$; MIS Quarterly $\left(4^{\circ}\right)$; Accounting Organizations and Society $\left(5^{\circ}\right)$; e Journal of Management Studies $\left(10^{\circ}\right)$. Também a avaliação das palavras-chave mais utilizadas nesses 357 artigos demonstra a penetração da Teoria da Estruturação no âmbito organizacional. Dentre as palavras-chave de maior ocorrência, destacam-se o termo "organização" - o segundo em número de ocorrências - figurando em 54 dos artigos pesquisados, enquanto "gestão" aparece em 28 deles. 
Constata-se que, não obstante as críticas recebidas, a Teoria da Estruturação tem sido utilizada em uma série de estudos em uma extensa gama de áreas, inclusive naquelas relacionadas aos estudos no âmbito organizacional. Apesar disso, e na tentativa de superar as limitações apontadas pelos vários críticos de Giddens, Stones (2005) propôs uma reformulação da teoria que ele chama de Strong Structuration Theory ("Teoria da Estruturação Forte"). Na próxima seção, serão apresentadas as concepções principais da "Teoria da Estruturação Forte" para que se possa, a seguir, indicar algumas possibilidades de utilização em estudos organizacionais.

\section{4 "Teoria da Estruturação Forte" (Strong Structuration Theory )}

Conforme discutido anteriormente, a Teoria da Estruturação foi alvo de várias críticas e revisões ao longo das três últimas décadas. Por meio de uma revisão dessas críticas, Stones (2005, p. 1-2) propõe uma nova ontologia para a perspectiva estruturacionista que revê alguns de seus conceitos, avalia as apreciações feitas, incorpora algumas das recomendações surgidas nesses embates e agrega conceitos de outras perspectivas teóricas. Esse novo arcabouço possibilita, no entendimento do autor, uma articulação entre a "ontologia-em-geral" proposta por Giddens e a "ontologia in situ" que ele propõe seja incorporada na análise estruturacionista (Stones, 2005, p.1-2).

De acordo com Stones (2005, p. 12-13), Giddens, ao se concentrar majoritariamente nos aspectos ontológicos gerais da Teoria da Estruturação, negligenciando as dimensões epistemológicas e metodológicas, direciona seu empreendimento teórico em uma forma demasiadamente ampla. Como alternativa, Stones (2005) propõe a "Teoria da Estruturação Forte" que busca empregar as principais virtudes da Teoria da Estruturação - principalmente o conceito de dualidade da estrutura - em um escopo mais restrito evitando, assim, as ambições generalistas de Giddens.

No entendimento de Stones (2005, p. 76-81), Giddens pecou ao privilegiar somente o nível filosófico que ele denomina ontologia-em-geral - na formulação da Teoria da Estruturação. A ontologia in situ é a saída encontrada pelo autor para superar essa limitação. Se a ontologia-em-geral se preocupa com "estruturas" e "agentes", em um sentido amplo, a ontologia in situ lida com estruturas e agentes particulares, mas em um nível intermediário, entre o nível ontológico abstrato e o nível ôntico - a especificidade de um dado ente na realidade. Segundo ele, uma abordagem ontológica intermediária possibilita a análise de conceitos ontológicos abstratos de forma escalonada ou relativa.

Ao mesmo tempo, ele defende que a "Teoria da Estruturação Forte" aceita e supera outra das críticas apontadas na Teoria da Estruturação: as dificuldades de sua utilização em pesquisa empíricas (STONES, 2005, p. 12-13). Na visão de Stones (2005, p. 3234), a Teoria da Estruturação de Giddens negligencia, em larga medida, as dimensões epistemológicas e metodológicas o que é, segundo ele, uma das razões principais para seu subaproveitamento, restringindo-a a um espaço demasiadamente limitado - a dimensão ontológica. Ele alerta, no entanto, que não está defendendo o abandono das questões ontológicas em favor de uma preocupação maior com a epistemologia e a metodologia. O que se defende é apenas um equilíbrio entre as dimensões. Para alcançar esse equilíbrio ele se propõe a:

[...] abordar esse déficit epistemológico insistindo que referências devem ser feitas a todo o "pacote" estruturacionista, incluindo não apenas a ontologia mas também problemáticas e tipos de questões particulares, e temas metodológi$\cos$ - incluindo decomposição metodológica $e$ reflexividade, assim como a identificação de etapas de pesquisa analiticamente distintas - $e$ as relações entre tudo isso e evidência empírica. (STONES, 2005, p. 34, tradução nossa)

Vislumbra-se, aqui, a pertinência de utilização da "Teoria da Estruturação Forte" nos estudos organizacionais. Ao privilegiar uma abordagem centrada em níveis intermediários, abre-se a possibilidade de investigação de problematizações vinculadas às organizações, assumindo-se, como Hodgson (2007, p. 96, tradução nossa), que as "[...] organizações são subconjuntos do conjunto de instituições, e instituições, são subconjuntos das estruturas sociais". Nessa perspectiva, a organização situa-se claramente em um nível intermediário entre a agência (ou o ator) e as estruturas mais amplas. 
Ao se adequar a ontologia e a epistemologia estruturacionistas a esses preceitos, o pesquisador pode, por exemplo, falar de mais ou menos cognoscitividade dos agentes em determinada organização, ao invés de falar sobre "a cognoscitividade" dos agentes em geral. Pode, também, verificar o número de consequências - intencionais ou impremeditadas - que resultam de uma ação específica no âmbito organizacional assim como delimitar clusters específicos de estruturas que são passiveis de serem modificadas por um ou mais agentes in situ - um conjunto de organizações, uma única organização ou, até mesmo, um departamento de uma organização - no lugar de tentar avaliar o impacto da ação do "agente" (em geral) na "estrutura". (STONES, 2005)
Objetivando operacionalizar essa abordagem, Stones (2005, p. 84-94) propõe uma nova forma de caracterizar a estruturação, dividindo a dualidade da estrutura em quatro aspectos distintos, mas interligados de forma cíclica. Segundo ele, a natureza quadripartite da estruturação é composta por: 1) estruturas externas que condicionam a ação e que têm uma existência autônoma do agente in focus; 2) estruturas internas dentro do agente, que podem ser divididas em duas: estruturas internas conjunturalmente específicas $e$ disposições gerais, ou habitus ${ }^{2}$ ); 3) agência ativa, que incluí as formas que o agente utiliza para recorrer, de forma rotineira ou crítica, às suas estruturas internas; e 4) resultados, que podem ser eventos singulares ou efeitos sobre as estruturas internas e externas (Figura 2).

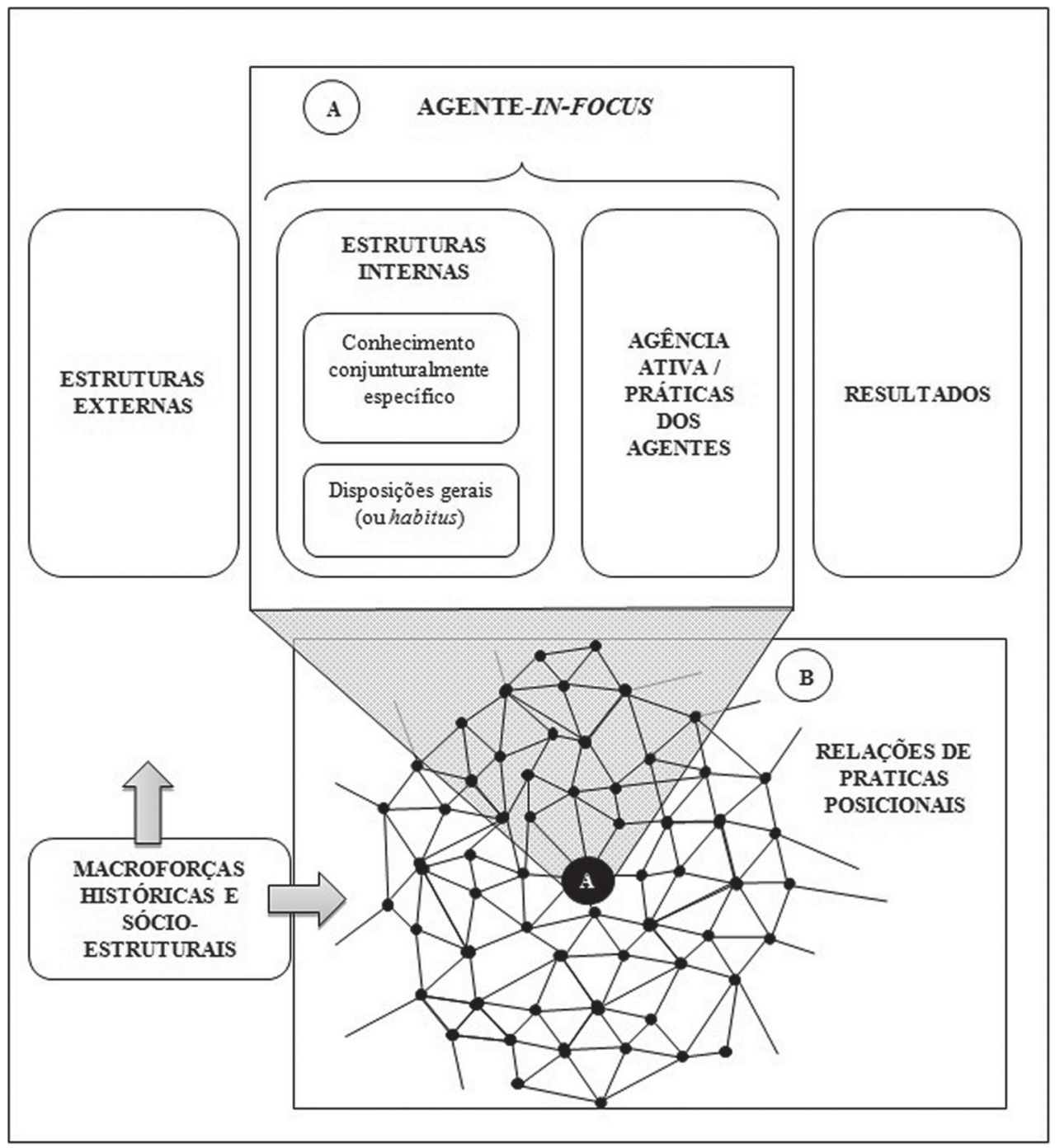

Figura 2: Agente in focus dentro de um campo de relações de práticas posicionais Fonte: Adaptada de Stones (2005, p. 85-128) 
Para complementar sua proposta, Stones (2005, p. 83-86) enfatiza na "Teoria da Estruturação Forte", o conceito de práticas posicionais ${ }^{3}$ (position-practice), definidas por Cohen (1989, p. 210) como constituintes institucionalizados (estruturados e reproduzíveis) da vida social. Práticas posicionais podem apresentar propriedades diversas como, por exemplo, posições institucionalizadas, identidades posicionais, o senso de prerrogativas e obrigações, dentre outras.

A inter-relação, sempre presente, entre práticas posicionais é, do mesmo modo, uma característica fundamental dessa abordagem. Conforme afirma Cohen (1989, p. 211), "[...] essas relações são reproduzidas por meio de diversos modos de integração social em circunstâncias de copresença, assim como via modos de integração entre agentes ausentes". Ele exemplifica afirmando que ao falar de um pai ou de um médico; de um pastor ou de um executivo, não se está referindo somente à sua identidade posicional, mas, também, a um conjunto de práticas estruturadas cujos "encarregados da posição" (position-incubents) conseguem exercer. (COHEN, 1989, p. 210)

Na visão de Greenhalg e Stones (2010, p. 1.288), uma prática posicional é uma posição social, com práticas e identidades associadas. Ao mesmo tempo, há uma rede de relações sociais (as relações de práticas posicionais) que a reconhece e apoia e que inclui várias reciprocidades institucionais, relações assimétricas de poder e infraestruturas institucionais.

Stones (2005, p. 65, tradução nossa) insere as práticas posicionais (e suas relações) no nível intermediário de seu modelo de análise. Ao fazê-lo, ele reconhece que

[...] o complexo aparato das relações de práticas posicionais oferece uma ligação útil do nível meso, por meio da qual concepções de forças históricas mais amplas e noções mais convencionais de estrutura, podem ser utilizadas em estudos baseados na "Teoria da Estruturação Forte".

Para Jack e Kholeif (2007, p. 8), essa ênfase permite ao pesquisador examinar as redes e relacionamentos entre clusters de agentes dentro de espaço delimitados - um governo, uma organização, ou até mesmo departamentos de uma empresa que seriam assumidas como um conjunto delimitado de práticas -posicionais, que apresentam, também, um circunscrito conjunto de relações de práticas posicionais.

Por último, o modelo da "Teoria da Estruturação Forte" agrega macroforças sociais e históricas que, inegavelmente, afetam a conduta dos agentes e conjunto de relações de práticas posicionais no qual ele está situado (Figura 2). Essa incorporação, no entanto se dá de forma seletiva. Para não incorrer no mesmo "suposto equívoco" generalizante de Giddens, Stones (2005, p. 127) defende que, em estudos estruturacionistas, a ênfase deve ser dada a clusters institucionais que têm algum grau de contingência em relação ao contexto no qual determinado processo de estruturação ocorre. Dessa forma, ele entende que se torna possivel estabelecer pontos de conexão entre as dimensões mais amplas (macroforças), aspectos-chave da dualidade da estrutura e a natureza quadripartite do ciclo de estruturação.

\section{Possibilidades de Utilização da "Teoria da Estruturação Forte" em Estudos Organizacionals: CONSIDERAÇÕES EPISTEMOLÓGICAS E
METODOLÓGICAS}

De acordo com Giddens (1989, p. 234-235), são possíveis dois tipos de enquadramentos metodológicos em pesquisas sociológicas. $\mathrm{Na}$ análise estratégica, o foco recairia sobre os modos como os atores sociais se valem das propriedades estruturais para a constituição de relações sociais. Já na análise institucional, as propriedades estruturais (regras e recursos) - assumidas como características cronicamente reproduzidas de sistemas sociais - tornam-se a preocupação central. Apesar da proposição dessa divisão de abordagens metodológicas, o autor recomenda que

[...] na medida em que se trata de uma diferença de ênfase, não existe uma linha divisória nítida que possa ser traçada entre esses dois tipos, $e$ cada um deles, crucialmente, tem de ser, em princípio, completado por uma concentração na dualidade da estrutura. (GIDDENS, 1989, p. 234-235)

À semelhança de Giddens, Stones (2005, p. 118-123) propõe dois tipos de agrupamentos me- 
todológicos (methodological bracketings). A análise da conduta do agente - o primeiro deles - recorre à categoria ontológica da cognoscitividade (componente das estruturas internas do agente) e conduz a análise "dentro" do agente; da monitorização reflexiva; de sua hierarquia de propósitos, seus motivos e desejos; da forma como ele conduz a ação $e$ a interação no transcurso da vida. O foco recai, assim, nos processos reflexivos e pré-reflexivos de seleção desenvolvidos pelo agente, na identificação dos aspectos relevantes das estruturas conjunturalmente específicas internas que são mais pertinentes ao contexto de ação imediata e que levam à reconciliação com a agência ativa e à estrutura de disposições-gerais de significado do agente.

Já á análise do contexto do agente, o segundo tipo, recomenda que se olhe "através" do agente; podendo ser usada para analisar "[...] o terreno que confronta um agente, o terreno que constitui o leque de possibilidades e limites do possível" (STONES, 2005, p. 122, tradução nossa). Nesse agrupamento metodológico, a cognoscitividade, enquanto estrutura interna conjunturalmente-específica, também é elemento fundamental. A perspectiva, contudo, é de "dentro para fora" do agente, que leva à análise dos nexos sociais de interdependências, direitos e obrigações, assimetrias de poder e condições sociais e consequências da ação.

A visão de Stones (2005, p. 123) aqui diverge da visão de Giddens uma vez que, em contraste com a análise institucional, a análise do contexto do agente não trata as instituições como regras e recursos cronicamente reproduzidos nem assume que as propriedades institucionais dos contextos de interação são metodologicamente "dadas". Nesse tipo de análise, a configuração mesorrelacional imediata das práticas-posicionais institucionais é tratada como um objeto de investigação significativo. Ao fazer isso, essa abordagem reconhece a necessidade de investigar as habilidades e o conhecimento dos atores dentro de um contexto de ação.
Isso limita o foco de atenção ao centro das manifestações das forças estruturais mais amplas dentro do horizonte prático de ação do agente, percebido por ele e pelo pesquisador (STONES, 2005, p. 83). Essa postura converge com a crítica de Parker (2000, p. 107, tradução nossa), pois ele entende que os "[...] 'estruturacionistas'4 devem teorizar em uma temporalidade 'intermediária', aquela das relações entre eventos específicos e agência".

Nessa discussão, em um aspecto Stones concorda com Giddens. Ambos entendem que a investigação pode (e no caso de Giddens, deve) utilizar ambos os agrupamentos metodológicos. No caso de Stones (2005, p. 123), ele defende que a utilização conjunta vai depender da questão e do objeto de pesquisa. Para ele há, em alguns casos, a necessidade de se utilizar aspectos tanto da análise da conduta do agente quanto da análise do contexto do agente. O que determinará a forma de abordagem será o objeto de estudo e o tipo de questão de pesquisa formulado. Segundo Stones (2005, p. 117), os objetos de estudo da "Teoria da Estruturação Forte" são, por definição, aqueles que envolvem questões in situ, que contemplem a hermenêutica dos agentes combinada com diagnósticos estruturais. Nesse sentido, o modelo proposto de estruturação quadripartite e os tipos de agrupamentos metodológicos indicam as possibilidades de abordagem do problema dado. Naturalmente, em função do tipo da questão de pesquisa proposta, o foco inicial recairá sobre um dos quatro aspectos do ciclo de estruturação e um dos tipos de agrupamento empregado.

O Quadro 1 sistematiza e exemplifica tipos de questão de pesquisa, com os aspectos do ciclo quadripartite de estruturação enfocados e o agrupamento metodológico adequado. O quadro apresenta, ainda, questões que indicam possibilidades de pesquisa baseadas na perspectiva da "Teoria da Estruturação Forte". 


\begin{tabular}{|c|c|c|}
\hline AgRUPAMENTO METODOLÓGICO & Focos DE PESQUISA & QUESTÕES DE PESQUISA \\
\hline \multirow[b]{2}{*}{ Análise da conduta do agente } & $\begin{array}{l}\text { Estruturas internas: } \\
\text { - Disposições gerais/habitus }\end{array}$ & $\begin{array}{l}\text { - Quais são os quadros gerais de significação do } \\
\text { agente in focus? } \\
\text { - Quais estruturas (ou sistemas) atuam, de forma } \\
\text { plural, na formação das disposições gerais do } \\
\text { agente in focus? }\end{array}$ \\
\hline & $\begin{array}{l}\text { Conhecimento conjunturalmente-específico: } \\
\text { - quadro de significados e percepções do agente } \\
\text { sobre as possibilidades e constrangimentos } \\
\text { decorrentes das estruturas externas; } \\
\text { - integração prática do agente in focus à rede de } \\
\text { relações posicionais e/ou a hierarquização de seus } \\
\text { vários projetos de ação, baseada na percepção } \\
\text { das estruturas conjunturais }\end{array}$ & $\begin{array}{l}\text { - Como o agente in focus percebe as possibilidades } \\
\text { e constrangimentos provenientes das estruturas } \\
\text { externas? } \\
\text { - Como o agente in focus adapta seus projetos às } \\
\text { exigências de seu contexto estrutural imediato? }\end{array}$ \\
\hline \multirow[b]{2}{*}{ Análise do contexto do agente } & Clusters de estruturas externas & $\begin{array}{l}\text { - Quais são os clusters de estruturas externas mais } \\
\text { relevantes para o agente in focus? } \\
\text { - Quais são as relações de práticas-posicionais } \\
\text { que, rotineiramente, constituem esses clusters? }\end{array}$ \\
\hline & $\begin{array}{l}\text { Possibilidades de ação e de modificação estrutural, } \\
\text { admissível pelas estruturas externas, e os } \\
\text { constrangimentos e influências que essas estruturas } \\
\text { têm sobre agentes específicos }\end{array}$ & $\begin{array}{l}\text { - Quais são as consequências imediatas } \\
\text { (intencionais e não intencionais) de determinada } \\
\text { ação? } \\
\text { - Como essas consequências impactam as relações } \\
\text { de práticas-posicionais e as estruturas mais } \\
\text { amplas? }\end{array}$ \\
\hline
\end{tabular}

Quadro 1: Esquema de abordagens epistemológicas com a SST

Fonte: Adaptado de Stones (2005) e de Greenhalg e Stones (2010)

As questões apresentadas - que, cabe ressaltar, são apenas algumas, dentre uma série de outras cabíveis na perspectiva da "Teoria da Estruturação Forte" - permitem vislumbrar possibilidades interessantes de investigações na esfera dos estudos organizacionais. Estudos sobre aprendizagem organizacional, por exemplo, podem se valer da análise da conduta do agente para investigar tanto as disposições gerais quanto o conhecimento conjunturalmente-específico, utilizados pelo agente in focus no processo de aprendizagem.

Várias pesquisas nessa área com suporte estruturacionista já foram realizadas (BERENDS; BOERSMA; WEGEMMAN, 2003; FELDMAN; PENTLAND, 2003). Com a "Teoria da Estruturação Forte", no entanto, novas questões de pesquisa se abrem. Quais disposições gerais (esquemas interpretativos, hierarquia de valores, habilidades específicas, etc.) são relevantes no processo de aprendizagem organizacional? Como são formadas essas disposições? Que conhecimentos conjunturalmente-específicos são acionados nesse processo?
Outra possibilidade interessante de investigação na área organizacional com a utilização da "Teoria da Estruturação Forte" encontra-se nos estudos relacionados a redes. As concepções de práticas-posicionais e relações de práticas-posicionais viabilizam estudos sobre redes no nível meso, tanto intraorganizacionais quanto interorganizacionais. Ao empregar a análise do contexto do agente, questões de pesquisa que investiguem os clusters de estruturas externas podem ser formuladas, tentando, por exemplo, responder: quais são as redes de relações de práticas-posicionais mais relevantes para determinado agente in focus em uma determinada organização? A quais constrangimentos e incentivos, decorrentes dessas redes de relações -posicionais, o agente in focus está sujeito? Quais as consequências (intencionais ou não) que as ações do agente in focus têm sobre as redes de relações de práticas-posicionais?

Estudos nessa perspectiva já começam, inclusive, a ser desenvolvidos. Greenhalg e Stones (2010), por exemplo, valendo-se da "Teoria da Estruturação Forte", associada à Teoria Ator-Rede, propõe uma perspectiva 
teórica que busca explicar o que acontece - nos níveis micro, meso e macro - quando se implanta, em serviços de saúde, sistemas avançados de tecnologia da informação. Eles argumentam que, nessa perspectiva, as relações de práticas-posicionais podem ser analisadas como uma rede sociotécnica, nas quais as tecnologias em conjunto com os seres humanos, tornam-se actants.

Por último, cabe salientar que Stones (2005, p. 126), apesar de priorizar o nível meso na "Teoria da Estruturação Forte", não descarta a abordagem de questões de maior escopo. Combinando-se vários aspectos dos anteriormente abordados, processos particulares de estruturação, que envolvem vários atores em um período de tempo relativamente extenso, podem ser investigados por meio de uma estratégia composta (composite strategy). Nesses casos, a noção de estruturação quadripartite estará presente e atuante, mas não apenas em uma relação entre agente in focus e contexto estrutural externo. Várias relações semelhantes serão estabelecidas ao mesmo tempo $e$ em diferentes locais. O autor ressalta, contudo, que quanto maior a abrangência do estudo, mais limitada torna-se a possibilidade de investigação da cognoscitividade do agente, uma vez que, a capacidade de monitoração reflexiva, fica prejudicada. Também nesse caso, acredita-se que a "Teoria da Estruturação Forte" pode contribuir para os estudos organizacionais, ao permitir a análise de objetos de pesquisa constituídos por mais de um agente in focus.

\section{Considerações Finais}

Partindo da premissa da importância das organizações na Teoria da Estruturação (relembrando que para Giddens (1987, p. 155) “[...] o mundo moderno é o mundo das organizações [...]") e tendo em vista a utilização expressiva da perspectiva giddensiana em estudos ligados às organizações (pesquisa na base WoS indicaram isso), acredita-se que a "Teoria da Estruturação Forte" pode, com os acréscimos e revisões feitos à Teoria da Estruturação, desempenhar papel semelhante no futuro próximo. Essa crença baseia-se, principalmente, na adequação da ontologia in situ, sugerida por Stones (2005), aos estudos que tenham, como objeto de pesquisa, as organizações, os agentes que nela atuam e os contextos de interação nos quais elas se situam.
Diversas possibilidades de investigação no âmbito organizacional se descortinam a partir dessa concepção, em campos como aprendizagem organizacional, impacto da tecnologia nas organizações, cultura organizacional, comunicação organizacional, dentre outras. Ao mesmo tempo, a ênfase da "Teoria da Estruturação Forte" na rede de relações de práticas-posicionais, indica um caminho nos quais questões relacionadas ao estudo de redes intra e interorganizacionais podem ser elucidadas.

Tem-se a esperança de que esse artigo possa - mesmo em restrito espaço de exposição - ter apresentado as ideias centrais que norteiam a "Teoria da Estruturação Forte". Não era pretensão, e as limitações do tipo de trabalho não permitiam, que se aprofundasse nas filigranas teóricas da "Teoria da Estruturação Forte" - que, diga-se de passagem, é um trabalho de fôlego, de "refinamento" da Teoria da Estruturação. Mas se este trabalho despertar em algum leitor o interesse pela "Teoria da Estruturação Forte" e motivar sua utilização em estudos organizacionais, seu desdobramento maior terá sido alcançado. Obviamente que se recomenda, caso alguém queira se valer dessa abordagem teórica, uma leitura prévia dos trabalhos de Giddens, para que a "[...] inestimável contribuição para o debate em andamento entre agência e estrutura" (EDWARDS, 2006, p. 913), oferecida pela "Teoria da Estruturação Forte", possa ser utilizada, em sua plenitude, nos estudos organizacionais.

\section{REFERÊNCIAS}

\section{ALBANO, R.; MASINO, G.; MAGGI, B. The relevance} of Giddens structuration theory for organizational research. Bologna: Tao Digital Library, 2010.

Disponível em: <http://amsacta.unibo.it/2774/1/

RelevanceGiddensStructurationTheory.pdf > . Acesso em: 16 nov. 2011.

ALEXANDER, J. C.O novo movimento teórico. Revista Brasileira de Ciências Sociais, São Paulo, v. 2, 4, p. 5-28, 1987.

ARCHER, M. S. Morphogenesis versus structuration: on combining structure and action. The British Journal of Sociology, USA, v. 33, n. 4, dec. p. 455-483, 1982. 
BARLEY, S. R. Technology as an occasion for structuring: evidence from observations of CT scanners and the social order of radiology departments. Administrative Science Quarterly, USA, v. 31, p. 78-108, 1986.

BERARD, T. J. Rethinking practices and structures. Philosophy of the Social Sciences, USA, v. 35, n. 2, p. 196-230, 2005.

BERENDS, H.; BOERSMA, K.; WEGGEMAN, M. The structuration of organizational learning. Human Relations, USA, v. 56, 9. p. 1.035-1.056, 2003.

\section{BHASKAR, R. The possibility of naturalism: a} philosophical critique of the contemporary human sciences. 3. ed. Abingdon: Routledge, 1998.

BRYANT, C. G. A.; JARY, D. Anthony Giddens: a global social theorist. In: (Ed.). The contemporary

Giddens. New York: Palgrave Macmillan, 2001. p. 3-39.

COHEN, I. J. Structuration theory: Anthony Giddens and the constitution of social life. New York: St. Martin's Press, 1989.

DESANCTIS, G.; POOLE, M. S. Capturing the complexity in advanced technology use: adaptive structuration theory.

Organization Science, USA, v. 5, n. 2, p. 121-147, 1994.

DOMINGUES, J. M. Teorias sociológicas no século XX. Rio de Janeiro: Civilização Brasileira, 2008.

EDWARDS, T. Book Review: developments toward the operationalization of structuration theory. Organization, USA, v. 13, n. 6. p. 911-13, 2006.

FELDMAN, M. S.; PENTLAND, B. T. Reconceptualizing organizational routines as a source of flexibility and change. Administrative Science Quarterly, USA, v. 48, n. 1, mar., p. 94-118, 2003.

GIDDENS, A. A constituição da sociedade. São Paulo: Martins Fontes, 1989.

Dualidade da estrutura: agência e estrutura. Tradução de Octávio Gerneiro. Oeiras: Celta, 2000. 105 p.

O Estado-Nação e a violência: segundo volume de uma crítica contemporânea ao materialismo histórico. Tradução de Beatriz Guimarães. São Paulo: EDUSP, 2008.
Funcionalismo: aprés la lutte. In:

Em defesa da sociologia: ensaios, interpretações e tréplicas. Tradução de Roneide V. Majer e Klaus B. Gerhardt. São Paulo: UNESP, 2001. (p. 115-160)

Novas regras do método sociológico: uma crítica positiva das sociologias compreensivas. Rio de Janeiro: Zahar, 1978.

Social theory and modern sociology.

Stanford: Stanford Univ. Press, 1987.

GREENHALGH, T.; STONES, R. Theorising big it programmes in healthcare: strong structuration theory meets actor-network theory. Social Science \& Medicine, USA, v. 70, n. 9, p. 1.285-1.294, 2010.

HODGSON, G. M. Institutions and individuals: interaction and evolution. Organization Studies, USA, v. 28, n. 1. p. 95-116, 2007.

JACK, L.; KHOLEIF, A. Introducing strong structuration theory for informing qualitative case studies in organization, management and accounting research.

Qualitative Research in Organizations and Management, USA, v. 2, n. 3. p. 208-225, 2007.

JUNQUILHO, G. S. Condutas gerenciais e suas raízes: uma proposta de análise à luz da teoria da estruturação. Revista de Administração Contemporânea, Rio de Janeiro, v. 7, Edição Especial, p. 101-120, 2003.

MACHADO-DA-SILVA, C. L.; GUARIDO FILHO, E. R.; ROSSONI, L. Campos organizacionais: seis diferentes leituras e a perspectiva de estruturação. Revista de Administração Contemporânea, Rio de Janeiro, Edição Especial, p. 159-196, 2006.

MOUZELIS, N. Restructuring Structuration Theory. Sociological Review, USA, v. 37, n. 4, p. 613-635, 1989.

PARKER, J. Structuration. Buckingham: Open University Press, 2000.

PHIPPS, A. Empirical applications of structuration theory. Geografiska Annaler, USA, Series B. Human Geography, v. 83b, n. 4, p. 189-204, 2001.

PIRES, R. P. Apresentação. In: GIDDENS, A. Dualidade da estrutura: agência e estrutura. Tradução de Octávio Garneiro. Oeiras: Celta, 2000. 
POZZEBON, M. The influence of a structurationist view on strategic management research. Journal of Management Studies, USA, v. 41, n. 2, p. 247-272, 2004.

POZZEBON, M.; PINSONNEAULT, A. Challenges in conducting empirical work using structuration theory: learning from IT research. Organization Studies, USA, v. 26,9 , p. $1.353-1.376,2005$.

RANSON, S.; HININGS, B.; GREENWOOD, R. The structuring of organizational structures. Administrative Science Quarterly, USA, v. 25, p. 1-18, 1980.

REED, M. I. In praise of duality and dualism: rethinking agency and structure in organizational analysis.

Organization Studies, USA, v. 18, n. 1, p. 21-42, 1997.

RODRIGUES, A. L. Tensões entre econômico e social: uma proposta de análise à luz da teoria da estruturação.

Revista de Administração de Empresas, São Paulo, v. 48 , n. 2 , p. 37-50, 2008.

SCHILLING, C. Towards an embodied understanding of the structure/agency relationship. The British Journal of Sociology, USA, v. 50, n. 4, p. 543-562, 1999.

SEWELL JR., W. H. A theory of structure: duality, agency, and transformation. American Journal of Sociology, USA, v. 98, n. 1, p. 1-29, 1992.

STONES, R. Structuration theory. New York: Palgrave MacMillan, 2005.

THOMPSON, B. J. The theory of struturation. In: HELD, D.; THOMPSON, B. John. Social theory of modern societies. Cambridge: Cambridge University Press, 1989.

WHITTINGTON, R. Putting Giddens into action: social systems and managerial agency. Journal of

Management Studies, USA, v. 29, 6, p. 693-712, 1992.

\section{Notas}

1. Como ainda não há uma tradução consolidada para Strong Strcturation Theory em português, optou-se por utilizar neste trabalho, nossa tradução - "Teoria da Estruturação Forte" - entre aspas.

2. Segundo Stones (2005, p. 87-88), seu conceito de disposições gerais se aproxima do habitus de Pierre Bordieu e refere-se às habilidades que os agentes possuem (esquemas culturais, classificações, cadeias associativas, etc.) que são empregadas (tacitamente; "sem pensar") nas práticas cotidianas de acordo com as especificidades de localização no tempo e no espaço.

3. Na tradução de Álvaro Cabral para o livro A constituição da sociedade (1989), o termo positionpractice foi traduzido como "posição-prática". Adotou-se, neste trabalho, "práticas-posicionais", tradução para o termo feita por Gilson C. C. de Sousa em Teoria social hoje (1999).

4. Parker (2000) denomina tanto Bordieu como Giddens de "estruturacionistas". 